(C) [2007] IEEE. Reprinted, with permission, from Guo, Youguang; Zhu, Jianguo; Lu, Hai Yan. 'Effects of armature reaction on the performance of a claw pole motor with soft magnetic composite stator by finite-element analysis', IEEE Transactions On Magnetics, Vol. 43, no. 3, pp. 1072-1077. This material is posted here with permission of the IEEE. Such permission of the IEEE does not in any way imply IEEE endorsement of any of the University of Technology, Sydney's products or services. Internal or personal use of this material is permitted. However, permission to reprint/republish this material for advertising or promotional purposes or for creating new collective works for resale or redistribution must be obtained from the IEEE by writing to pubs-permissions@ieee.org. By choosing to view this document, you agree to all provisions of the copyright laws protecting it. 


\title{
Effects of Armature Reaction on the Performance of a Claw Pole Motor with Soft Magnetic Composite Stator by FEA
}

\author{
YouGuang Guo, Senior Member, IEEE, Jian Guo Zhu, Senior Member, IEEE, and Hai Yan Lu
}

\begin{abstract}
This paper investigates the effects of armature reaction on the performance of a three-phase three-stack claw pole motor with soft magnetic composite stator core by using three-dimensional finite element analysis (FEA), which is an effective approach to accurately compute the parameters and performance such as the back electromotive force $(e m f)$, core losses and winding inductance at various saturation levels. The motor investigated is rated as $500 \mathrm{~W}$ at $1800 \mathrm{rpm}$ when the stator current is 4.1 A, driven by a sensorless brushless DC scheme. Due to the armature reaction, the back emf produced by the rotor permanent magnets and the developed torque is reduced by about $3.3 \%$ at the rated load, and the core losses increase drastically by $41 \%$ from no-load to full-load. The winding inductance is computed with different loads at different rotor angles.
\end{abstract}

Index Terms - 3D finite element analysis, armature reaction, claw pole motor, core loss, soft magnetic composite, winding inductance.

\section{INTRODUCTION}

F INITE ELEMENT method (FEM) enables accurate analysis to study the effects of armature reaction, especially for electromagnetic devices with three-dimensional (3D) magnetic flux paths such as claw pole and transverse flux machines. The machine investigated in this paper is a three-phase three-stack claw pole motor with soft magnetic composite (SMC) stator core, rated as $500 \mathrm{~W}$ at $1800 \mathrm{rpm}$ when the stator current is 4.1 A, driven by a sensorless brushless DC (BLDC) scheme [1]. SMC materials produced by powder metallurgical techniques are very suitable for construction of 3D flux machines due to their isotropic magnetic and thermal properties, low eddy current loss, and nearly net-shape fabrication process with good tolerance and surface finish [2]. Claw pole motors have significant flux leakage between the adjacent poles, and due to the low magnetic permeability SMC cores encourage the leakage, which is of 3D nature.

The motor studied was designed to take full advantages of SMC's unique properties. For example, taking advantage of the $3 \mathrm{D}$ isotropic magnetic property, the magnet is designed to

Manuscript received October 31, 2005

Y. G. Guo and J. G. Zhu are with the Faculty of Engineering, University of Technology, Sydney, PO Box 123, Broadway, NSW 2007, Australia (phone: +61-2-9514-7903; e-mails: youguang@eng.uts.edu.au, joe@eng.uts.edu.au).

H. Y. Lu is with the Faculty of Information Technology, University of Technology, Sydney, PO Box 123, Broadway, NSW 2007, Australia. be axially longer than the claw pole as the flux can flow into the claw poles via the side surfaces [1]. The initial design is carried out by the conventional equivalent magnetic circuit method based on the shape and dimensions of available SMC preforms. The 3D finite element analysis (FEA) of magnetic field is then conducted to validate the results and fine tune the design to obtain the optimum solution.

Fig. 1 illustrates the magnetically relevant parts of the rotor and stator of the claw pole motor and Table 1 lists the major dimensions and parameters. The motor employs an interior stator made by SMC and an exterior rotor with $20 \mathrm{NdFeB}$ permanent magnets (PMs) per phase on the inner surface of the mild steel rotor yoke.

This paper investigates the effect of armature reaction on the motor performance when the magnetic circuit saturates. Magnetic field FEAs are conducted at no-load, half-load and full-load, respectively. Due to the armature reaction, the curve of stator winding flux produced by rotor PMs against the rotor position is deviated, causing a reduction in the fundamental component of flux, and hence the back electromotive force (emf) and the developed torque. The flux density loci in the finite elements in the iron core are disturbed, causing increase of core losses. The winding inductance, another important parameter determining the motor performance, is also related to the armature reaction and is computed with different stator currents and rotor positions.

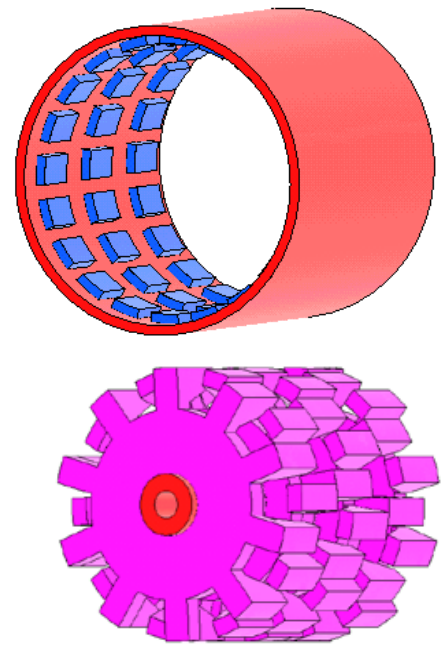

Fig. 1. Magnetically relevant parts of the SMC claw pole motor 
TABLE I

MAJOR DIMENSIONS AND PARAMETERS

\begin{tabular}{ll}
\hline \hline Dimensions and parameters & Quantities \\
\hline Stator outer radius (mm) & 40 \\
Effective stator axial length (mm) & 93 \\
Rotor outer radius (mm) & 47 \\
Rotor inner radius (mm) & 41 \\
Magnet dimensions & OD88 x ID82 x 15mm arc $12^{\circ}$ \\
Main airgap length (mm) & 1 \\
Number of poles & 20 \\
Rated frequency (Hz) & 300 \\
Number of phases & 3 \\
Rated power (W) & 500 \\
Rated line-to-neutral voltage (V) & 64 \\
Rated phase current (A) & 4.1 \\
Rated speed (rev/min) & 1800 \\
Rated torque (Nm) & 2.65 \\
Rated efficiency (\%) & 81 \\
Rated temperature rise $\left({ }^{\circ} \mathrm{C}\right)$ & 75 \\
\hline \hline
\end{tabular}

\section{3D FEA OF ARMATURE REACTION}

When a current flows in the stator winding, it produces a magnetic field to interact with the air gap field due to the rotor magnets, causing a disturbance [3]. The effect of the armature reaction is not difficult to analyze if the magnetic circuit is linear, but it becomes complex when the core material is saturated, increasing the reluctance of the magnetic circuit and deviating the motor performance. The FEA is an ideal tool to include the detailed structure, dimensions and non-linear material property.

Because of the magnetic independence between phases and the structural symmetry, it is only required to analyze the magnetic field in a pole pitch of one stack, as shown in Fig. 2.

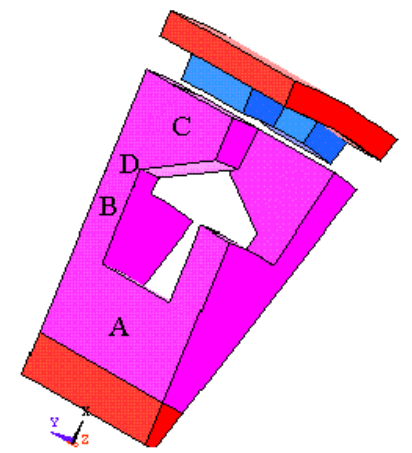

Fig. 2. FEA solution region of one pole-pitch

The scalar magnetic potentials on the two radial planes should obey the constrains of half-periodical conditions as

$\varphi_{m}(r, \Delta \theta / 2, z)=-\varphi_{m}(r,-\Delta \theta / 2,-z)$

where $\Delta \theta=18^{\circ}$ is the angle of one pole pitch.

Fig. 3a illustrates the no-load flux density vectors with lengths proportional to the magnitudes at the rotor position where the magnets share the same axes as the claw poles respectively. Both the major and leakage flux paths are threedimensional. Fig. 3b plots the flux density vectors generated by the rated stator current only, showing that the major flux path is different from that of the magnetic field produced by the PMs.

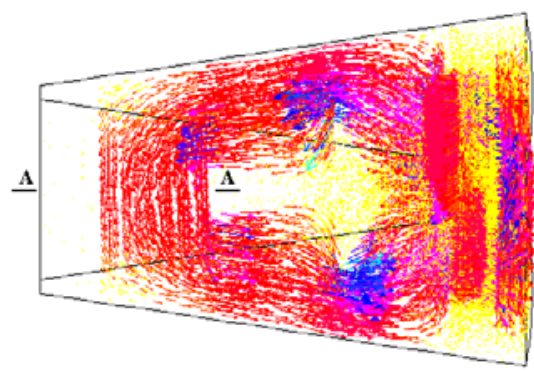

(a)

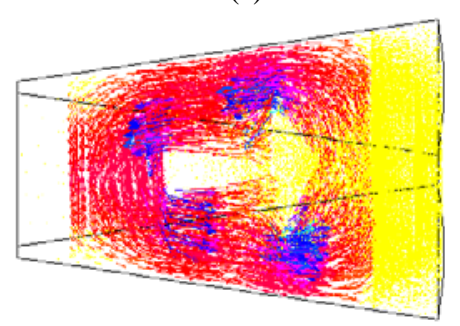

(b)

Fig. 3. Magnetic flux density vectors by: (a) PM only, (b) stator current only.

\section{PM FLUX}

The PM flux, which is defined as the flux component linking the stator winding produced by the rotor PMs, is calculated based on the cross-section area A-A (Fig. 3a). If the magnetic circuit is linear, the armature reaction does not affect the flux. But if the magnetic circuit is saturated, the PM flux could be deviated, as well as the motor performance such as the back emf and the developed torque.

The FEAs are performed at no-load, half-load, and full-load, respectively, and the curves of PM flux against the rotor angular position are shown in Fig. 4. To consider the effect of saturation, firstly the non-linear analysis is conducted with the excitations of both PMs and armature current $i_{1}$, and the permeability of each element is saved. Then under these conditions, a linear analysis is conducted with the PMs only so that the PM flux can be obtained. Under the condition of the optimum BLDC control, the stator current is in phase with the back emf, i.e. lagging the PM flux by $90^{\circ}$ electrical. The fundamental of the stator current can be determined by

$i_{1}=\sqrt{2} I_{1 r m s} \sin \theta$

where $1_{1 r m s}$ is the $r m s$ value of the stator current (4.1A for fullload), and $\theta$ the rotor angle with the zero position where the claw poles line up with the rotor PMs, as shown in Fig. 2.

The fundamental component of the stator flux produced by PMs at no-load is $0.480 \mathrm{mWb}$, decreasing to $0.476 \mathrm{mWb}$ at half-load, and $0.464 \mathrm{mWb}$ at full-load. The reduction of the $\mathrm{PM}$ flux due to armature reaction is $0.002 \mathrm{mWb} / \mathrm{A}$ from noload to half-load, and $0.006 \mathrm{mWb} / \mathrm{A}$ from half-load to fullload. The flux reduction is not linear with the armature current but increases drastically with the current. The loss of the flux fundamental, the back emf and developed torque at full-load due to armature reaction is about $3.3 \%$. 


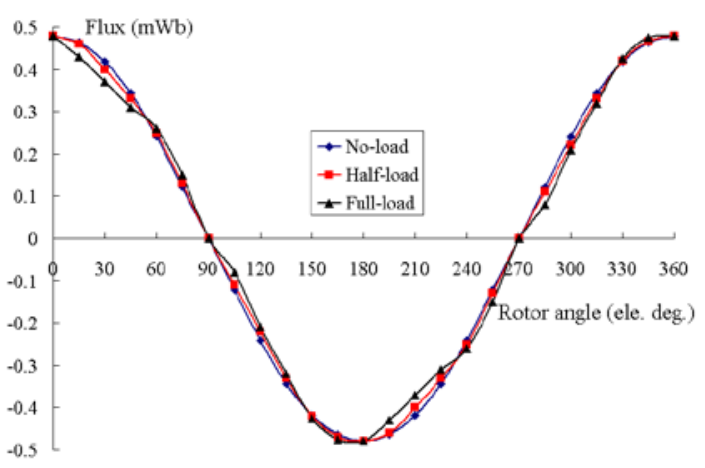

Fig. 4. Stator winding flux produced by PMs considering armature reaction

\section{CORE LOSSES}

Core loss prediction is a key issue in the design and optimization of electrical machines. Unlike the laminated machines, SMC ones have comparable core loss to the copper loss. The core loss calculation can be very complex because in claw pole motors the flux density patterns are quite complicated, particularly when the armature reaction is taken into account.

A comprehensive method has been used for predicting the core losses in SMC machines with 3D flux paths [4, 5]. Different formulations are applied for various flux density patterns such as alternating (1D), two-dimensional (2D) circularly or elliptically rotating, as summarized in the follows:

The alternating core loss is calculated by

$P_{a}=C_{h a} f B_{P}{ }^{h}+C_{e a}\left(f B_{P}\right)^{2}+C_{a a}\left(f B_{P}\right)^{1.5}$

and the core loss with circular flux density pattern by

$P_{r}=P_{h r}+C_{e r}\left(f B_{P}\right)^{2}+C_{a r}\left(f B_{P}\right)^{1.5}$

where

$$
\begin{aligned}
& \frac{P_{h r}}{f}=a_{1}\left[\frac{1 / s}{\left(a_{2}+1 / s\right)^{2}+a_{3}^{2}}-\frac{1 /(2-s)}{\left[a_{2}+1 /(2-s)\right]^{2}+a_{3}^{2}}\right] \\
& s=1-\frac{B_{P}}{B_{s}} \sqrt{1-\frac{1}{a_{2}^{2}+a_{3}^{2}}}
\end{aligned}
$$

The coefficients $C_{h a}, h, C_{e a}, C_{a a}, C_{e r}, C_{a r}, a_{1}, a_{2}, a_{3}$, and $B_{s}$ can be obtained from the measured core losses on the SMC sample under various frequencies, $f$, and various peak flux densities, $B_{p}$ by the curve fitting technique [4].

The core loss with elliptical $\boldsymbol{B}$ is predicted from the alternating and circularly rotating core losses by

$$
P_{t}=R_{B} P_{r}+\left(1-R_{B}\right)^{2} P_{a}
$$

and minor axes of the elliptical $\boldsymbol{B}$ locus, and $P_{r}$ and $P_{a}$ are the core losses with a circular $\boldsymbol{B}$ with $B_{\operatorname{maj}}=B_{\min }=B_{p}$ and an alternating $\boldsymbol{B}$ with peak value $B_{p}$, respectively.

The core losses are computed based on elements. The $\boldsymbol{B}$ pattern in each element is obtained by the 3D magnetic field FEA. Figs. 5, 6 and 7 plot the flux density loci and the three components at no-load, half-load and full-load in the middle of the stator yoke (Point A of Fig. 2), the side disk (Point B), and the claw pole (Point C), respectively.

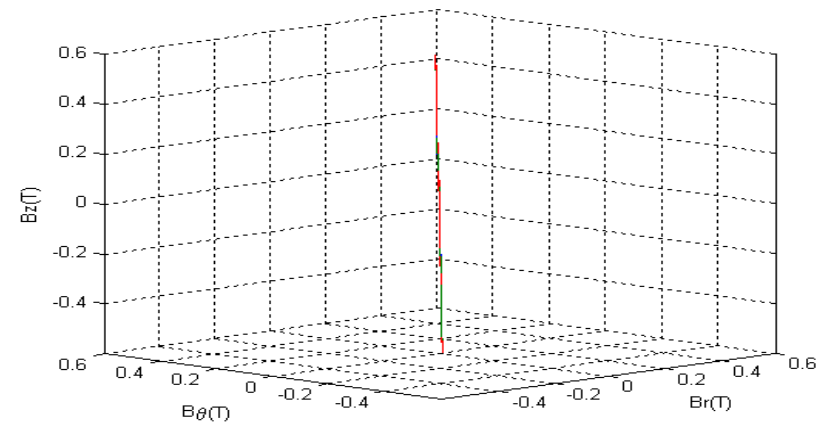

(a) All $\boldsymbol{B}$ patterns with different loads are $1 \mathrm{D}$ alternating in z-axis

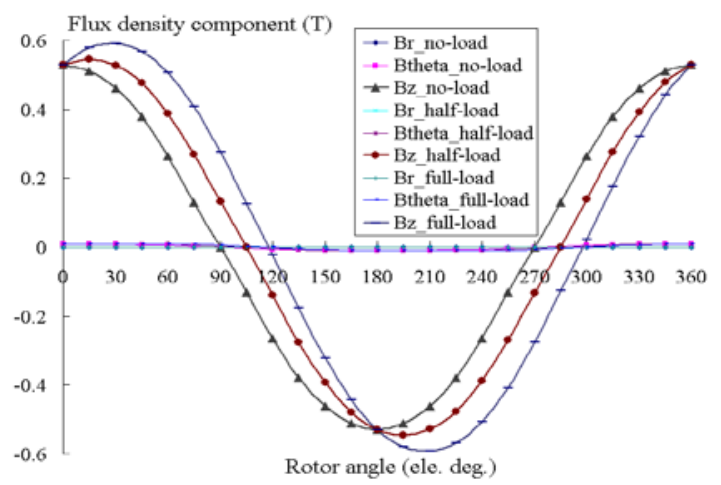

(b) The dominant z-component of $\boldsymbol{B}$ is deviated by armature reaction

Fig. 5. (a) Loci and (b) three components of flux density at Point A of Fig. 2

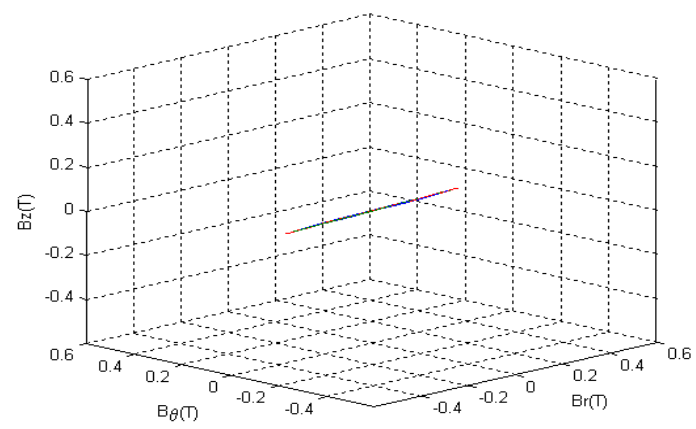

(a) All $\boldsymbol{B}$ patterns with different loads are $1 \mathrm{D}$ alternating mainly in the r-axis 


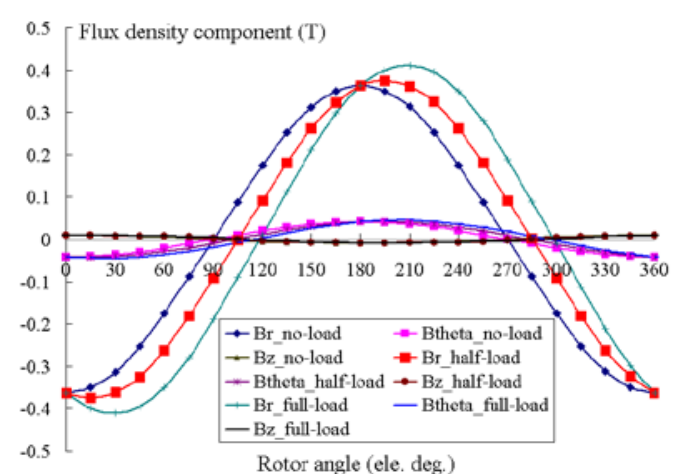

(b) The dominant r-component and a non-negligible $\theta$-component of $\boldsymbol{B}$ are deviated due to armature reaction

Fig. 6. (a) Loci and (b) three components of flux density at Point B of Fig. 2

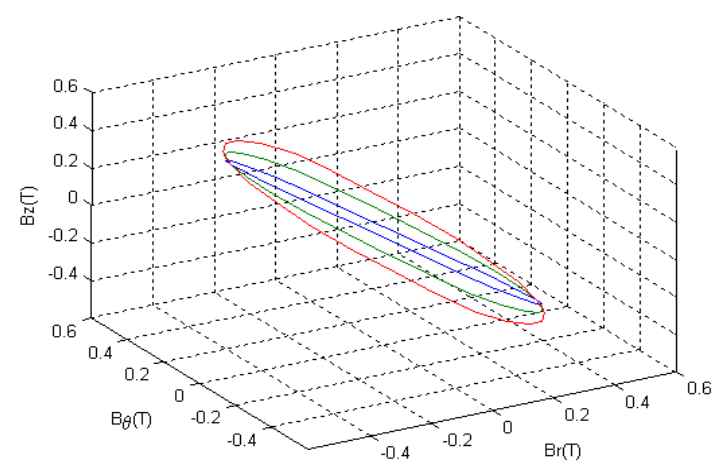

(a) All $\boldsymbol{B}$ patterns at different loads are circularly rotating in 3D space: inner locus for no-load, middle one for half-load, and outer one for full-load

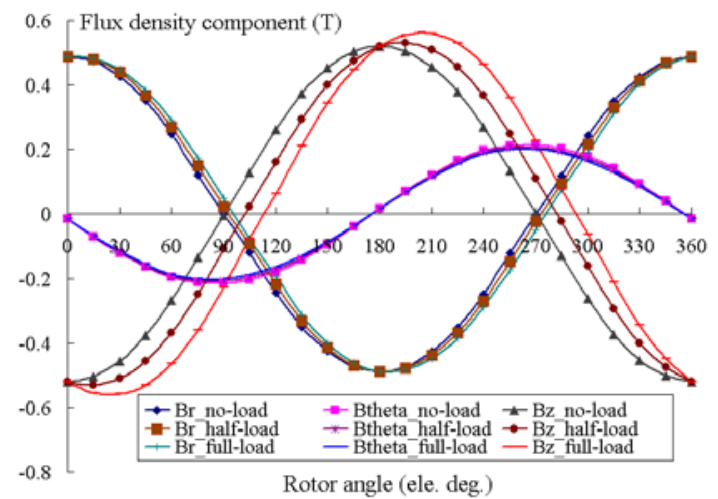

(b) All $\boldsymbol{B}$ components are non-negligible and deviated by armature reaction

Fig. 7. (a) Loci and (b) three components of flux density at Point $C$ of Fig. 2

It can be seen that the flux density loci are disturbed by the armature reaction. For any flux density locus of an element, the three components can always be expanded into Fourier series as

$$
B_{i}(t)=\sum_{k=0}^{\infty}\left[B_{i s k} \sin (2 \pi k f t)+B_{i c k} \cos (2 \pi k f t)\right]
$$

where $i=r, \theta, z, B_{r}, B_{\theta}$, and $B_{z}$ are the radial, circumferential and axial components of $\boldsymbol{B}$, respectively. Each harmonic consists of two parts: $\mathbf{n}_{\text {sk }} \sqrt{{B_{r s k}}^{2}+B_{\theta s k}^{2}+B_{z s k}^{2}} \sin (2 \pi k f t)$

$\mathbf{n}_{\mathrm{ck}} \sqrt{{B_{r c k}}^{2}+B_{\theta c k}{ }^{2}+B_{z c k}^{2}} \cos (2 \pi k f t)$

where $\boldsymbol{n}_{\boldsymbol{s k}}$ and $\boldsymbol{n}_{\boldsymbol{c k}}$ are the unit vectors, determined by $B_{r s k}, B_{\theta s k}$ and $B_{z s k}$, and $B_{r c k}, B_{\theta c k}$ and $B_{z c k}$, respectively. The two parts generally form an elliptical trajectory in a plane determined by $\boldsymbol{n}_{\boldsymbol{s k}}$ and $\boldsymbol{n}_{\boldsymbol{c} \boldsymbol{k}}$. The major axis $B_{k m a j}$ and the minor axis $B_{k m i n}$ can be obtained by a coordinate rotation for the standard equation.

For each elliptically rotating flux density harmonic, the loss can be predicted from the corresponding alternating and rotational losses according to the axis ratio of the elliptical flux density. Therefore, the total loss is

$P_{t}=\sum_{e=1}^{N e} \sum_{k=0}^{\infty}\left[P_{r k} R_{B K}+\left(1-R_{B K}\right)^{2} P_{a k}\right]$

where $N_{e}$ is the number of elements of the core, $R_{B K}=B_{k \min } / B_{k m a j}$ is the axis ratio of the $k$-th harmonic flux density, $P_{r k}$ is the purely rotational loss with flux density $B_{k m a j}$, and $P_{a k}$ is the alternating loss with $B_{p}=B_{k m a j}$.

The core loss is calculated as $58.0 \mathrm{~W}$ at no-load, but goes up to $67.4 \mathrm{~W}$ at half-load, and further to $81.8 \mathrm{~W}$ at full-load. The core loss increment is non-linearly related to the armature reaction, e.g. 4.6 W/A from no-load to half-load, and 7.0 W/A from half-load to full-load. The calculation of core losses has been validated by the experimental results on the SMC claw pole motor prototype [6]. As an example, Fig. 8 illustrates the computed and measured core losses at no-load at different rotor speeds. The calculations agree well with the experimental results.

The no-load core loss is measured by using the "dummy stator method", which includes two measurements. In the first measurement, the prototype is driven by a DC motor and the power fed into the DC motor is measured. The second measurement is conducted while the SMC stator of the prototype is replaced by a wood tube. The difference between the readings of electromagnetic power for the two cases gives the core loss. Here, it is assumed that the core loss and mechanical loss of the DC driving motor are constant at certain rotor speed. The dummy stator is used to simulate the windage. The prototype is assumed to have the same windage and friction loss for the SMC stator and the dummy stator if it is driven at the same speed.

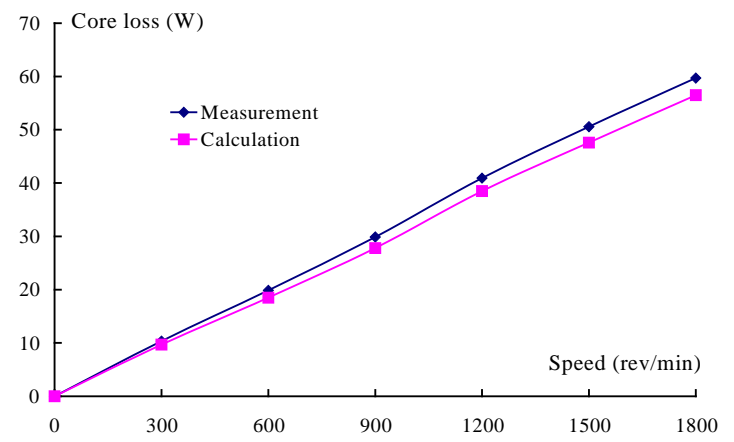

Fig. 8. Core loss calculation and measurement at no-load 


\section{INDUCTANCE CALCULATION}

The self-inductance of a phase winding is calculated by

$L_{1}=\frac{2 W_{f}}{i_{1}^{2}}$

Like the calculation of PM flux, two-step analyses are conducted to consider the effect of saturation, i.e. a non-linear analysis to find and save the permeability of each element at the operating point, and then a linear analysis with the saved permeabilities and a stator current $i_{1}$ only to determine the magnetic co-energy $W_{f}$. It should be noted that the saturation is caused by both the PMs and stator current, which is determined by (2) when the motor operates under the optimum BLDC control condition.

This calculation is in fact the secant inductance, i.e. the slope of the linearized characteristic of flux-linkage versus current through the origin and the operating point. However, the behavior of an electric circuit is governed by the so-called incremental inductance, along the tangential line at the operating point. In this paper, the incremental inductance is computed by a modified method, developed from the so-called incremental energy method [7, 8], and the enhanced incremental energy method [9].

The modified incremental energy method (MIEM) calculates the incremental inductance by the following steps [10]: (I) Perform non-linear magnetic field analysis with the excitation of both the stator current and PMs; (II) Determine and save the differential permeability in each element; (III) Conduct linear analysis with the saved differential permeabilities and only a perturbed current, $\Delta i$; (IV) Calculate the co-energy increment $\Delta W_{c}$ and then the incremental inductance by (9). In fact, the perturbed current in (III) can be large since the magnetic field analysis is linear.

$$
L_{i n c} \approx \frac{2 \Delta W_{c}}{(\Delta i)^{2}}
$$

Fig. 9a illustrates the computed secant and incremental inductances versus rotor angle with different loads. It is seen that the armature reaction affects the inductance patterns, which are important for the motor's dynamic performance and control strategy.

The inductance was measured by the AC voltage-current method with the rotor locked. Fig. 9b plots the measured inductances with a small AC current $(0.2 \mathrm{~A}, 500 \mathrm{~Hz})$, as well as the computed inductances at no-load for comparison. The computation in general agrees with the experimental results.

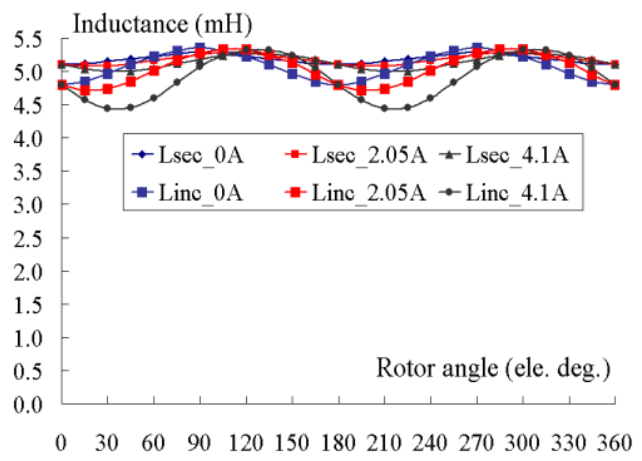

(a)

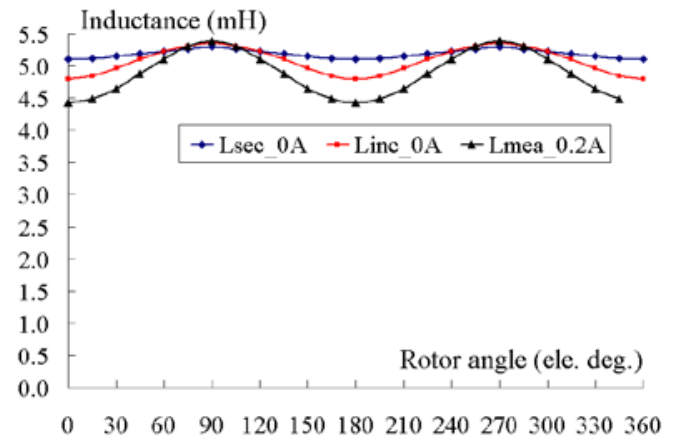

(b)

Fig. 9. Phase winding inductances: (a) calculation, (b) measurement.

\section{CONCLUSION}

This paper studies the effects of armature reaction on the parameters, such as the PM flux, core loss and winding inductance, and performance in a claw pole SMC motor. The armature reaction reduces the developed torque and changes the winding inductance. Particularly, the core loss increases drastically due to the armature reaction and should be properly considered in the design and application of electromagnetic devices.

\section{REFERENCES}

[1] Y.G. Guo, J.G. Zhu, P.A. Watterson, W.M. Holliday, and W. Wu, "Improved design and performance analysis of a claw pole permanent magnet SMC motor with sensorless brushless DC drive," IEEE Int. Conf. Power Electronics \& Drive Sys., Singapore, Nov. 2003, pp. 704-709.

[2] "The latest development in soft magnetic composite technology," SMC Update, Reports of Höganäs AB, Sweden, 1997-2005. Available at http://www.hoganas.com/, see News then SMC Update.

[3] P.R. Upadhyay, K.R. Rajagopal, and B.P. Singh, "Effect of armature reaction on the performance of an axial-field permanent-magnet brushless DC motor using FE method," IEEE Trans. Magn., Vol. 40, No. 4, July 2004, pp. 2023-2025.

[4] Y.G. Guo, J.G. Zhu, J.J. Zhong, and W. Wu, "Core losses in claw pole permanent magnet machines with soft magnetic composite core," IEEE Trans. Magn., Vol. 39, No. 5, Sept. 2003, pp. 3199-3201.

[5] Y.G. Guo, J.G. Zhu, Z.W. Lin, and J.J. Zhong, "Measurement and Modeling of Core Losses of Soft Magnetic Composites under 3D Magnetic Excitations in Rotating Motors", IEEE Trans. Magn., Vol. 41, No. 10, Oct. 2005, pp. 3925-3927. 
[6] Y.G. Guo, J.G. Zhu, P.A. Watterson, and W. Wu, "Development of a claw pole permanent magnet motor with soft magnetic composite stator," Australian J. of Electrical \& Electronic Eng., Vol. 2, No. 1, 2005, pp. 21-30.

[7] N.A. Demerdash and T.W. Nehl, "Electrical machinery parameters and torques by current and energy perturbations from field computations - Part I: theory and formulation," IEEE Trans. Energy Conversion, Vol. 14, No. 4, 1999, pp. 15071513.

[8] N.A. Demerdash and T.W. Nehl, "Electrical machinery parameters and torques by current and energy perturbations from field computations - Part II: applications and results," IEEE Trans. Energy Conversion, Vol. 14, No. 4, 1999, pp. 15141522.

[9] M. Gyimesi and D. Ostergaard, "Inductance computation by incremental finite element analysis,” IEEE Trans. Magn., Vol. 35, No. 3, May 1999, pp. 1119-1122.

[10] Y.G. Guo, J.G. Zhu, and H.Y. Lu, “Accurate determination of parameters of a claw pole motor with SMC stator core by finite element magnetic field analysis," IEE Proc. - Electric Power Application, UK, Vol. 153, No. 4, July 2006, pp. 568-574.

YouGuang Guo (S’02-M’05-SM'06) was born in Hubei, China in 1965. He received the B.E. degree from Huazhong University of Science and Technology (HUST), China in 1985, the M.E. degree from Zhejiang University, China in 1988, and the PhD degree from University of Technology, Sydney (UTS), Australia in 2004, all in electrical engineering.

From 1988 to 1998, he lectured in the Department of Electrical Engineering, HUST. From March 1998 to July 2000, He was a visiting research fellow in the Center for Electrical Machines and Power Electronics, Faculty of Engineering, UTS. He is currently an ARC (Australia Research Council) postdoctoral research fellow at UTS.

His research fields include measurement and modeling of magnetic properties of magnetic materials, numerical analysis of electromagnetic field, motor design and optimization, power electronics and control of electrical appliance. He has published over 100 technical papers in these fields.

Jian Guo Zhu (S'93-M'96-SM'03) is the Professor of Electrical Engineering and Director for the Center for Electrical Machines and Power Electronics at University of Technology, Sydney (UTS), Australia. He received his BE in 1982 from Jiangsu Institute of Technology, China, ME in 1987 from Shanghai University of Technology, China, and Ph.D in 1995 from UTS, Australia. His research interests are: electromagnetics, magnetic properties of materials, electrical machines and drives, power electronics, and renewable energy systems.

Hai Yan Lu is with the Faculty of Information Technology, University of Technology, Sydney (UTS). She gained her Bachelor and Master of Electrical Engineering in Harbin Institute of Technology, China in 1985 and 1988, respectively. She achieved her $\mathrm{PhD}$ in Faculty of Engineering, UTS, Australia, in 2002. Her current research interests are optimal design of electromagnetic devices, modeling and numerical simulation of magnetic materials, soft computing techniques and applications in power systems and power market.

Jinjiang Zhong was born in Heilongjiang Province, China, in 1963. $\mathrm{He}$ received the B.E. from Wuhan University of Science and Technology, China in 1987, and Ph.D. from University of Technology, Sydney (UTS), Australia in 2003. He is currently a research fellow in the Center for Electrical Machines and Power Electronics, UTS. His research interest includes measurement and modelling of magnetic properties of magnetic materials under 2-D and 3 -D vector magnetizations. 